\title{
Predictors of Successful Decannulation Using a Tracheostomy Retainer in Patients with Prolonged Weaning and Persisting Respiratory Failure
}

\author{
Stephan Budweiser ${ }^{a, b}$ Tobias Baur ${ }^{b}$ Rudolf A. Jörres ${ }^{c}$ Florian Kollert $^{b, d}$ \\ Michael Pfeifer ${ }^{\text {b, e }}$ Frank Heinemann ${ }^{b}$ \\ ${ }^{a}$ Division of Pulmonary and Respiratory Medicine, Department of Internal Medicine III, RoMed Clinical Center \\ Rosenheim, Rosenheim, ${ }^{b}$ Center for Pneumology, Donaustauf Hospital, Donaustauf, ${ }^{C}$ Institute and Outpatient \\ Clinic for Occupational, Social and Environmental Medicine, Ludwig-Maximilian University, Munich, \\ ${ }^{\mathrm{d}}$ Department of Rheumatology and Clinical Immunology, University Medical Centre, Freiburg, and e Division of \\ Respirology, Department of Internal Medicine II, University of Regensburg, Regensburg, Germany
}

\section{Key Words}

Prolonged weaning $\cdot$ Chronic respiratory failure $\cdot$

Tracheostomy $\cdot$ Noninvasive ventilation

\begin{abstract}
Background: For percutaneously tracheostomized patients with prolonged weaning and persisting respiratory failure, the adequate time point for safe decannulation and switch to noninvasive ventilation is an important clinical issue. $\mathbf{O b}$ jectives: We aimed to evaluate the usefulness of a tracheostomy retainer (TR) and the predictors of successful decannulation. Methods: We studied 166 of 384 patients with prolonged weaning in whom a TR was inserted into a tracheostoma. Patients were analyzed with regard to successful decannulation and characterized by blood gas values, the duration of previous spontaneous breathing, Simplified Acute Physiology Score (SAPS) and laboratory parameters. Results: In 47 patients (28.3\%) recannulation was necessary, mostly due to respiratory decompensation and aspiration. Overall, $80.6 \%$ of the patients could be liberated from a tracheostomy with the help of a TR. The need for recannulation was associated with a shorter duration of spontaneous breathing within the last $24 / 48 \mathrm{~h}(\mathrm{p}<0.01$ each), lower arterial oxygen tension $(p=0.025)$, greater age $(p=0.025)$, and a
\end{abstract}

higher creatinine level $(p=0.003)$ and SAPS $(p<0.001)$. The risk for recannulation was $9.5 \%$ when patients breathed spontaneously for $19-24 \mathrm{~h}$ within the $24 \mathrm{~h}$ prior to decannulation, but $75.0 \%$ when patients breathed for only $0-6 \mathrm{~h}$ without ventilatory support ( $p<0.001$ ). According to ROC analysis, the SAPS best predicted successful decannulation [AUC 0.725 (95\% Cl: 0.634-0.815), p < 0.001]. Recannulated patients had longer durations of intubation $(p=0.046)$, tracheostomy $(p=0.003)$ and hospital stay $(p<0.001)$. Conclusion: In percutaneously tracheostomized patients with prolonged weaning, the use of a TR seems to facilitate and improve the weaning process considerably. The duration of spontaneous breathing prior to decannulation, age and oxygenation describe the risk for recannulation in these patients.

Copyright $\odot 2012$ S. Karger AG, Basel

\section{Introduction}

The number of patients requiring difficult or prolonged weaning $[1,2]$ has increased greatly within the last decade [3]. This is due to the fact that patients in an intensive care unit (ICU) more often show chronic lung diseases, severe comorbidities, a greater age, or previously

\section{KARGER}

Fax +4161306 1234

E-Mail karger@karger.ch

www.karger.com (c) 2012 S. Karger AG, Basel

0025-7931/12/0846-0469\$38.00/0

Accessible online at:

www.karger.com/res
Stephan Budweiser, MD

Division of Pulmonary and Respiratory Medicine

Department of Internal Medicine III, RoMed Clinical Center Rosenheim

DE-83026 Rosenheim (Germany)

Tel. +498031 365 7101, E-Mail stephan.budweiser@ ro-med.de 
underwent complex interventions. To improve weaning outcome, these patients are often transferred to specialized weaning centers. During the prolonged weaning period, most patients receive a tracheostomy, which allows a reduction of sedation but also facilitates the weaning process by alleviating the work of breathing and the level of respiratory support [4]. Compared to surgical tracheostomy, the bedside percutaneous technique is increasingly used and is now considered as a safe and cost-effective procedure [5].

In contrast to the high level of evidence for tracheostomy, validated objective criteria for decannulation are lacking [6]. In clinically stable patients the tracheostomy tube is usually removed and the stoma covered with sterile gauze [7]. In patients with persisting respiratory failure and a prolonged need for at least intermittent ventilatory support, a switch to noninvasive ventilation (NIV) is common clinical practice in experienced weaning centers. Unfortunately, in percutaneously tracheostomized patients, the removal of the tracheal cannula regularly leads to an expeditious closure of the stoma, with the effect that a rapid and simple recannulation is impossible. In patients with chronic respiratory diseases and prolonged weaning, this is an important issue as a rapid deterioration of the respiratory function is not uncommon, particularly when NIV is ineffective or is not well accepted by the patient. In a situation like this, a reintubation or an emergency miniretracheostomy is inevitable [7]. To circumvent this problem, a tracheostomy retainer (TR), allowing immediate recannulation is increasingly used, although this device has not been studied in larger patient groups.

Based on these considerations, we assessed both the practicability and the clinical value of a TR and evaluated predictors for successful decannulation in percutaneously tracheostomized patients with prolonged weaning and persisting respiratory failure.

\section{Methods}

\section{Study Population and Weaning Concept}

We retrospectively evaluated all patients with prolonged weaning [2] who had been admitted to the regional weaning center at Donaustauf Hospital, Germany, between January 2003 and March 2009. Only patients with a percutaneous tracheostomy in whom a TR was successfully inserted for at least $1 \mathrm{~h}$ were considered. The standardized weaning concept, according to international guidelines [1], included a daily assessment of defined criteria for unsupported spontaneous breathing (i.e. resolution of the underlying disease, sufficient gas exchange, cardiovascular stability and adequate vigilance), the gradual decrease of ventilatory support and, if applicable, the extension of the duration of spon- taneous breathing with regard to respiratory distress, breathing frequency, pulse oxymetry and blood gas values.

The decision for the insertion of a TR was based on a clinical judgement considering a safe decannulation of patients showing a spontaneous breathing period of at least $6-8 \mathrm{~h}$ but also a high risk for recurrent or persisting chronic hypercapnic respiratory failure and a potential need for NIV. The decision for recannulation was made if the respiratory condition became worse as reflected in a significant increase in respiratory frequency and/or work of breathing, a decrease in transcutaneous oxygen saturation $\left(\mathrm{S}_{\mathrm{aO}_{2}}\right)$ and an impairment of blood gas values despite the use of NIV.

\section{Technical Issues of the Tracheostomy Retainer}

The TR (Teleflex Medical Inc., Kernen, Germany) consists of a silicon tube with an inner diameter of 6,8 or $10 \mathrm{~mm}$ that is reinforced in sections by a metal coil and has a slightly oblique, flexible, oval disc distally. After checking adequate consciousness, sufficient coughing and swallowing, the disc is cut according to the size of the tracheostoma. It is then inserted in a way that it touches the ventral part of the trachea, thereby completely sealing the tracheostomy channel. To circumvent dislocation, the TR is fixed with a screw closure and a neck band. Immediately after insertion, patients should breathe freely without stridor or relevant respiratory resistance. Bronchoscopy is performed to verify an optimal fitting without narrowing the trachea. When needed, NIV can be applied via a mask without leakage. In addition, patients can communicate and cough effectively. If recannulation is needed, the TR can be pulled out and replaced by a tracheal cannula. After successful weaning, the TR can be removed and the tracheostoma sealed. It is recommended that the period the TR is retained should not exceed 7 days.

\section{Data Collection}

Upon admission, demographic and anthropometric data, the duration of intubation and tracheostomy before decannulation and the total duration of hospital stay were assessed. Medical records were reviewed to reveal the initial cause of invasive mechanical ventilation, the major diagnosis and concomitant diseases. Laboratory parameters including blood count, C-reactive protein and serum creatinine were determined by standard procedures, and these values were taken into consideration at the day of TR insertion. This also applied to the Simplified Acute Physiology Score II (SAPS II) [8].

Before insertion of the TR, arterial blood gas values during spontaneous breathing, vital parameters and respiratory frequency were documented. The duration of spontaneous breathing (without ventilatory support) before decannulation was expressed in absolute values and percentages for the last 24 and $48 \mathrm{~h}$, the last 7 days and since the transfer of the patient to the weaning center.

In case of recannulation, the time point and the cause were documented. Successful decannulation was defined as 'no need for recannulation' during the total stay in the weaning centre. The ethics committee of the University of Regensburg gave approval for the study according to the retrospective and anonymous data analysis.

\section{Statistical Analysis}

Data are shown as median values and quartiles if not indicated otherwise. The Shapiro-Wilk test was applied to check for normal 
Fig. 1. Patient recruitment and weaning success. Summary: 61 (37.0\%) patients were discharged decannulated without ventilatory support, 72 (43.6\%) patients were discharged with home NIV, 32 (19.4\%) patients were discharged with tracheal cannula, 27 (16.4\%) with home IV, 5 (3.0\%) without home IV, 165 (100\%) patients in all were discharged (1 patient died in weaning center). ${ }^{1}$ Decannulation without the help of the TR. IV = Invasive ventilation; $\mathrm{TC}=$ tracheal cannula.

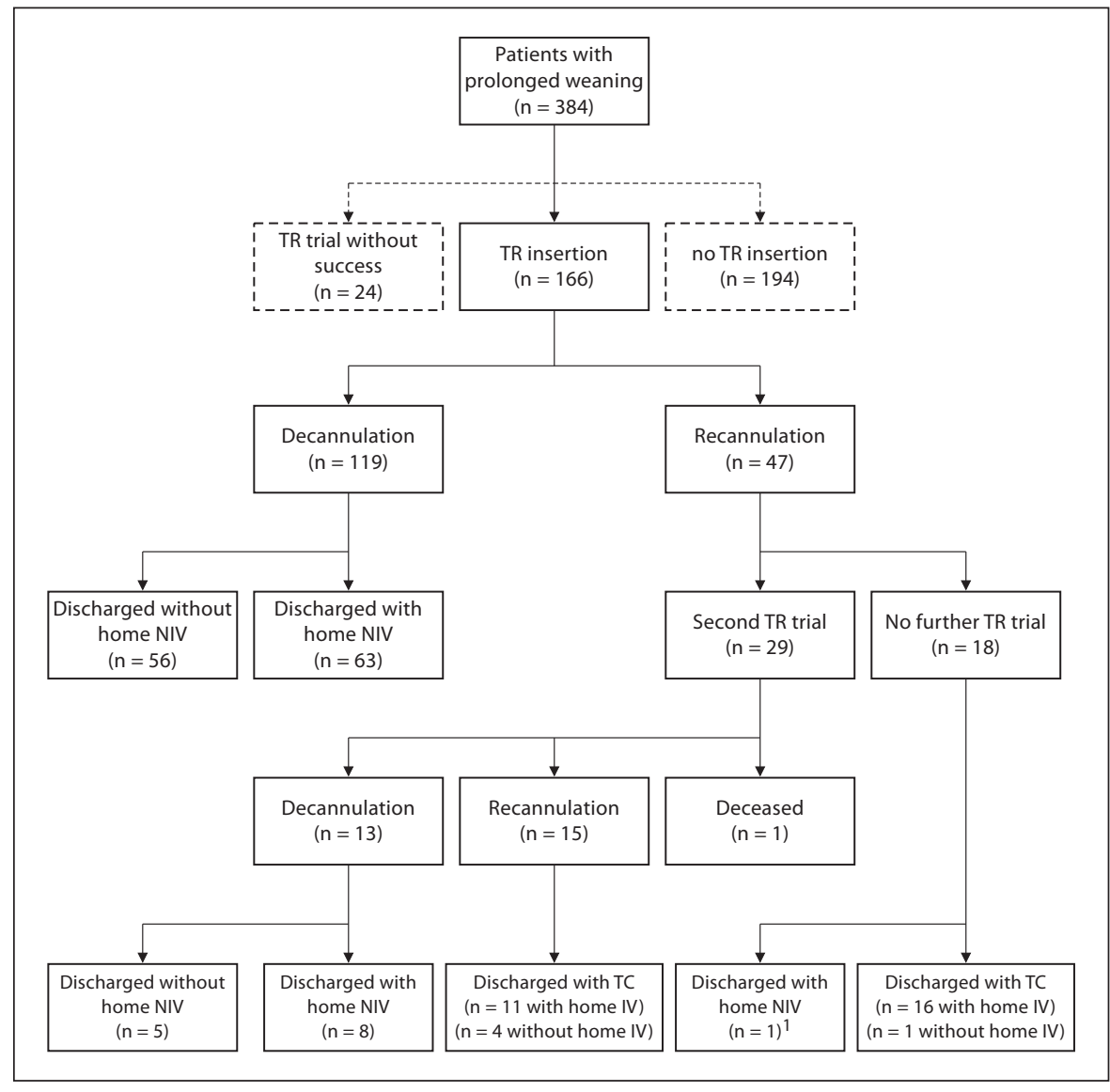

distribution. To compare baseline characteristics between groups, the unpaired t test or the nonparametric Mann-Whitney $U$ test were used. Binary variables were compared by the Fisher exact test. Receiver operating characteristic (ROC) curves were calculated to evaluate the predictive power of individual factors for successful decannulation. For all tests, a p value of $<0.05$ was considered significant. Calculations were performed using PASW statistics 17.0 (Chicago, Ill., USA).

\section{Results}

\section{Study Population}

Among 384 patients with prolonged weaning, 194 patients received no TR. The insertion of the TR failed in 24 patients (fig. 1). Thus, the study population in whom the TR could be inserted successfully comprised 166 patients (table 1). The median (quartiles) duration of intubation was $7.0(4.0,12.0)$ days. Patients had been tracheostomized for $31.0(23.0,43.0)$ days (fig. 2$)$. Most of them $(\mathrm{n}=$ 134) had been intubated due to cardiopulmonary failure including COPD exacerbation $(n=63)$, pneumonia $(n=$

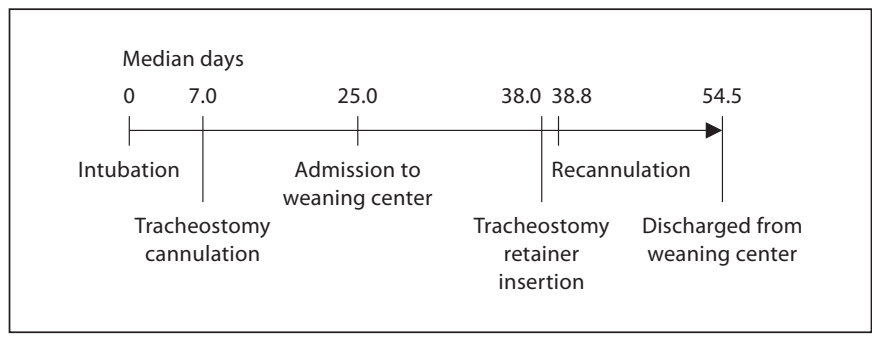

Fig. 2. Time-line of weaning from intubation to discharge. Median values are shown.

38), cardiac decompensation ( $\mathrm{n}=18)$, sepsis $(\mathrm{n}=8)$ or $\operatorname{ARDS}(\mathrm{n}=7)$. The remaining patients had a history of trauma $(n=5)$, surgical intervention $(n=21)$ or an unspecified cause for intubation $(n=6)$. Overall, 108 (65.1\%) patients had a diagnosis or history of COPD. Arterial hypertension (57.2\%), diabetes mellitus (31.3\%) and atrial fibrillation $(31.3 \%)$ were the most frequent chronic comorbidities. 


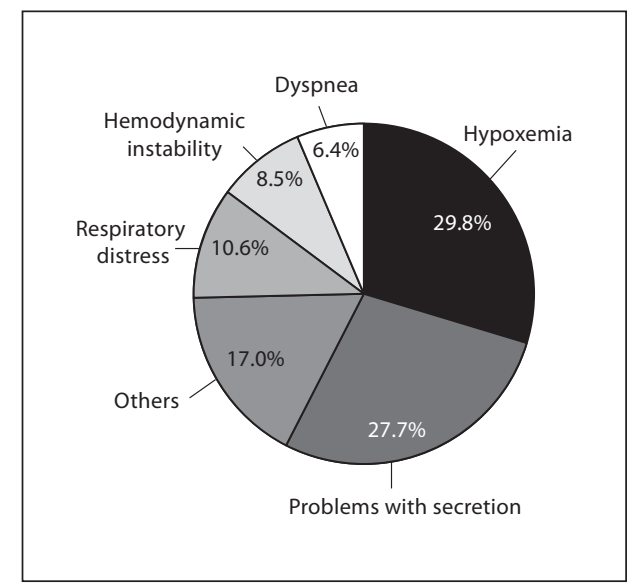

Fig. 3. Causes for recannulation at the first trial $(n=47)$, shown in percentages.

\section{Course of Weaning}

NIV was used after decannulation in 135 of 166 patients (81.3\%). The first decannulation was successful in 119 of the 166 patients (71.7\%). Among these, 63 patients were adapted to long-term intermittent noninvasive home mechanical ventilation (HMV), while 56 patients were discharged without ventilation (fig. 1). In 47 patients (28.3\%) recannulation was necessary. The causes are illustrated in figure 3. Most of these patients (29/47) underwent a further trial of decannulation with insertion of the TR. This was again unsuccessful in 15 patients who were then discharged with a permanent tracheostoma. In 13 patients, the second trial of removal of the TR resulted in final decannulation. One patient with a second trial of TR insertion died 17 days after insertion of the TR, probably because of respiratory decompensation despite NIV; the TR had been removed 12 days before death.

Seventeen of 18 patients with unsuccessful decannulation were discharged without a second trial of decannulation but with invasive HMV. Overall, $80.6 \%$ of patients could be liberated from tracheostomy (fig. 1).

\section{Predictors of Successful Decannulation}

Patients with a need for recannulation $(n=47)$ had lower arterial oxygen tension $\left(\mathrm{P}_{\mathrm{aO}_{2}}\right)$ but a greater age, creatinine level and SAPS II prior to decannulation compared to patients who were successfully decannulated ( $\mathrm{n}=119$; table 2). In addition, these patients presented with a shorter time period of spontaneous breathing within 24 and $48 \mathrm{~h}(\mathrm{p}<0.01 \mathrm{each})$ prior to decannulation (table 2). They also showed longer percent time periods of
Table 1. Characteristics of the study population (total $n=166$ )

\begin{tabular}{lc}
\hline Variable & $\begin{array}{l}\text { Median }(25 \text { th; 75th } \\
\text { percentiles })\end{array}$ \\
\hline Age, years $^{\mathrm{a}}$ & $68.0(60.8 ; 74.0)$ \\
BMI $^{\mathrm{b}}$ & $24.7(21.3 ; 29.7)$ \\
SAPS, points $^{\mathrm{a}}$ & $30.0(25.0 ; 34.0)$ \\
Duration of intubation, days $^{\mathrm{c}, \mathrm{e}}$ & $7.0(4.0 ; 12.0)$ \\
Duration of tracheostomy, days $^{\mathrm{d}, \mathrm{f}}$ & $31.0(23.0 ; 43.0)$ \\
Duration of hospitalization, days $^{\mathrm{a}, \mathrm{g}}$ & $29.5(22.0 ; 40.0)$
\end{tabular}

$\begin{array}{ll}\text { Blood gas analysis prior to TR insertion }^{\mathrm{a}} & \\ \mathrm{O}_{2} \text { flow, liters } & 2.0(1.5 ; 3.5) \\ \mathrm{pH} & 7.4(7.41 ; 7.48) \\ \mathrm{P}_{\mathrm{aCO}_{2}, \mathrm{kPa}} & 6.2(5.4 ; 7.1) \\ \mathrm{P}_{\mathrm{aO}_{2}}, \mathrm{kPa} & 9.5(8.3 ; 11.9) \\ \mathrm{BE}, \mathrm{mmol} / \mathrm{l} & 6.3(4.3 ; 8.6)\end{array}$

Vital signs prior to TR insertion ${ }^{\mathrm{a}}$

Systolic blood pressure, $\mathrm{mm} \mathrm{Hg}$

Respiratory rate, / $\mathrm{min}$

$130.0(120.0 ; 140.0)$

Heart rate, / $\mathrm{min}$

$19.0(16.0 ; 24.0)$

$90.0(70.0 ; 90.0)$

$\begin{array}{lc}\text { Laboratory parameters on the day of TR insertion } & \text { a } \\ \text { Hemoglobin, g/dl } & 10.2(9.5 ; 11.1) \\ \text { Hematocrit, \% } & 31.0(28.0 ; 34.0) \\ \text { Leukocytes, /nl } & 8.2(6.4 ; 10.7) \\ \text { Creatinine, } \mathrm{mg} / \mathrm{dl} & 0.8(0.6 ; 1.0) \\ \text { CRP, } \mathrm{mg} / \mathrm{dl} & 27.8(13.2 ; 48.4)\end{array}$

$\mathrm{BE}=$ Base excess; $\mathrm{CRP}=\mathrm{C}$-reactive protein $; \mathrm{P}_{\mathrm{aCO}_{2}}=$ arterial partial pressure of carbon dioxide; $\mathrm{P}_{\mathrm{aO}_{2}}=$ arterial partial pressure of oxygen.

${ }^{\mathrm{a}} \mathrm{n}=166$ patients (120 males, 46 females). ${ }^{\mathrm{b}} \mathrm{n}=151$ patients. ${ }^{\mathrm{c}} \mathrm{n}=147$ patients. ${ }^{\mathrm{d}} \mathrm{n}=163$ patients. ${ }^{\mathrm{e}}$ Duration from intubation up to tracheostomy. ${ }^{\mathrm{f}}$ Duration from tracheostomy up to insertion of TR. ${ }^{g}$ In the weaning center.

spontaneous breathing within the last 24 or $48 \mathrm{~h}$ since transfer to the weaning center (fig. 4).

Regarding spontaneous breathing within the last $24 \mathrm{~h}$ before recannulation, the risk for recannulation was $9.5 \%$ when the spontaneous breathing period was $19-24 \mathrm{~h}$, but $75.0 \%$ when patients breathed only $0-6 \mathrm{~h}$ without ventilatory support (fig. 5). In addition, the risk for recannulation was 10.6-fold (95\% CI: 1.5-73.7; p < 0.001) higher in patients with a need for NIV following decannulation compared to patients without. Using ROC analysis, the SAPS was most predictive for successful decannulation (fig. 6). Patients with a need for recannulation also had a longer duration of intubation, of tracheostomy prior to the first decannulation trial and of the total hospital stay (table 2). 
Table 2. Patients with recannulation in comparison to patients without recannulation

\begin{tabular}{|c|c|c|c|}
\hline Variable & $\begin{array}{l}\text { Without recannulation } \\
(\mathrm{n}=119)\end{array}$ & $\begin{array}{l}\text { With recannulation } \\
(\mathrm{n}=47)\end{array}$ & $\mathrm{p}$ value \\
\hline Male/female, $\mathrm{n}$ & $83 / 36$ & $37 / 10$ & $0.336^{1}$ \\
\hline Age, years & $68.0(58.0 ; 74.0)$ & $72.0(63.0 ; 76.0)$ & 0.025 \\
\hline BMI & $24.3(20.6 ; 30.0)$ & $25.3(22.6 ; 29.5)$ & 0.300 \\
\hline SAPS, points & $27.0(22.0 ; 33.0)$ & $34.0(30.0 ; 38.0)$ & $<0.001$ \\
\hline Duration of intubation ${ }^{\mathrm{a}}$, days & $6.0(3.0 ; 10.3)$ & $8.0(5.0 ; 13.0)$ & 0.046 \\
\hline Duration of hospitalization, days & $27.0(21.0 ; 36.0)$ & $40.0(31.0 ; 49.0)$ & $<0.001$ \\
\hline \multicolumn{4}{|l|}{ Blood gas analysis prior to TR insertion } \\
\hline $\mathrm{O}_{2}$ flow, liters & $2.0(1.0 ; 3.0)$ & $3.0(2.0 ; 4.0)$ & 0.011 \\
\hline $\mathrm{pH}$ & $7.44(7.41 ; 7.48)$ & $7.44(7.40 ; 7.47)$ & 0.970 \\
\hline $\mathrm{P}_{\mathrm{aCO}_{2}}, \mathrm{kPa}$ & $6.1(5.3 ; 7.0)$ & $6.4(5.4 ; 7.2)$ & 0.401 \\
\hline $\mathrm{P}_{\mathrm{aO}_{2}}, \mathrm{kPa}$ & $9.8(8.3 ; 12.6)$ & $8.9(8.2 ; 10.9)$ & 0.025 \\
\hline Respiratory rate, /min & $20.0(16.0 ; 24.0)$ & $18.0(16.0 ; 23.0)$ & 0.733 \\
\hline Heart rate, $/ \mathrm{min}$ & $90.0(70.0 ; 95.0)$ & $90.0(80.0 ; 90.0)$ & 0.824 \\
\hline \multicolumn{4}{|c|}{ Laboratory parameters on the day of TR insertion } \\
\hline Hemoglobin, g/dl & $10.2(9.5 ; 11.1)$ & $10.1(9.4 ; 11.1)$ & 0.788 \\
\hline Hematocrit, \% & $31.0(28.0 ; 34.0)$ & $31.0(28.0 ; 34.0)$ & 0.683 \\
\hline Leucocyte number, /nl & $8.3(6.9 ; 10.7)$ & $7.6(5.5 ; 11.1)$ & 0.120 \\
\hline Creatinine, $\mathrm{mg} / \mathrm{dl}$ & $0.7(0.5 ; 1.0)$ & $0.9(0.7 ; 1.2)$ & 0.003 \\
\hline $\mathrm{CRP}, \mathrm{mg} / \mathrm{dl}$ & $26.2(13.1 ; 43.4)$ & $32.1(15.3 ; 69.8)$ & 0.222 \\
\hline \multicolumn{4}{|c|}{ Duration of spontaneous breathing prior to decannulation } \\
\hline Within the last $24 \mathrm{~h}, \mathrm{~h}$ & $14.0(11.0 ; 23.5)$ & $12.0(9.0 ; 15.0)$ & 0.001 \\
\hline
\end{tabular}

\section{Discussion}

This study suggests two important clinical implications for patients with prolonged weaning. First, the application of a TR allows a safe decannulation of percutaneously tracheotomized patients with persisting respiratory failure. It facilitates a high success rate of decannulation while retaining the option of effective NIV. Secondly, in the decision of decannulation the duration of spontaneous breathing and oxygenation as well as a patient's age should be considered.

Despite the advantages of a tracheostoma for weaning in patients with prolonged ventilation $[9,10]$, it remains an unphysiological opening of the upper airway. During long-term use it impairs the clearance of secretions, may cause tracheal stenosis and has a negative impact on communication, swallowing and quality of life $[7,11]$. In patients with prolonged mechanical ventilation, weaning failure is associated with poor survival [11-13]. Moreover, in patients with invasive HMV via tracheostomy, longterm mortality and readmission rate are high [14]. Therefore, it appears important to liberate patients from a tracheostoma whenever possible and to keep the time with a tracheostoma as short as possible.

For patients in a stable clinical condition, expert guidelines for decannulation have been published [7]. Our study population, however, had a high risk for recurrent or a persisting chronic hypercapnic respiratory failure. 


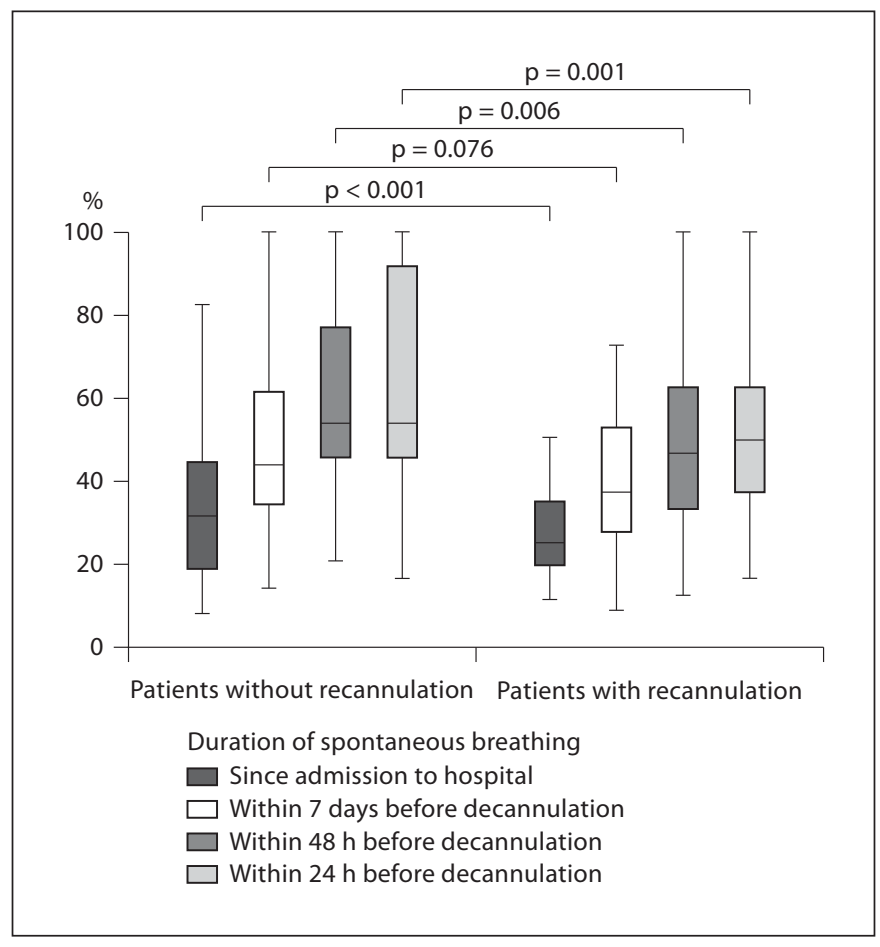

Fig. 4. Comparison of patients with $(n=47)$ and without $(n=119)$ recannulation at the first trial regarding spontaneous breathing in terms of percentage of the respective time interval. Values were compared by the Mann-Whitney U test.

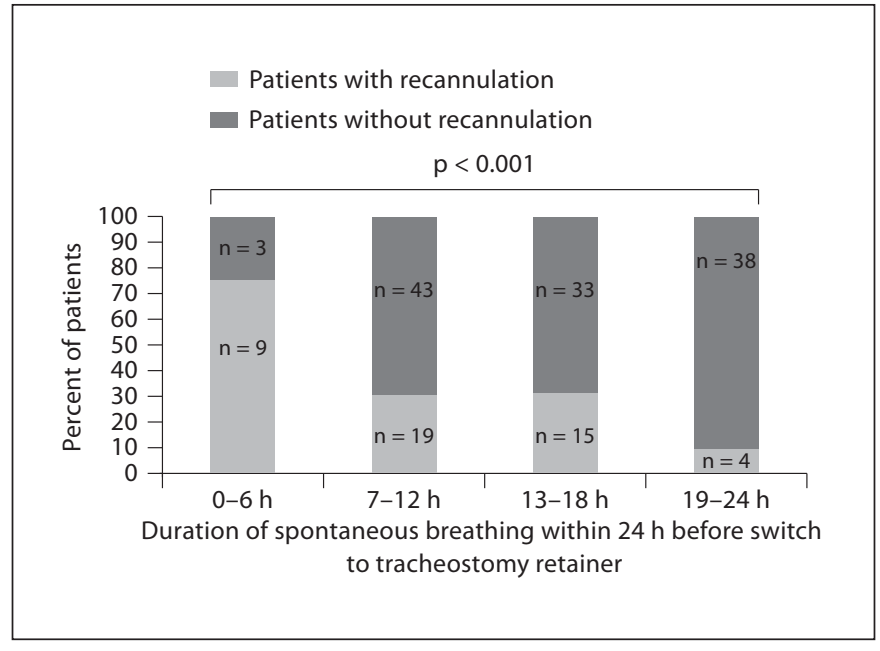

Fig. 5. Comparison of the risk for recannulation regarding the duration of spontaneous breathing (in absolute values) within the $24 \mathrm{~h}$ prior to decannulation. Data were compared using the $\chi^{2}$ statistics.

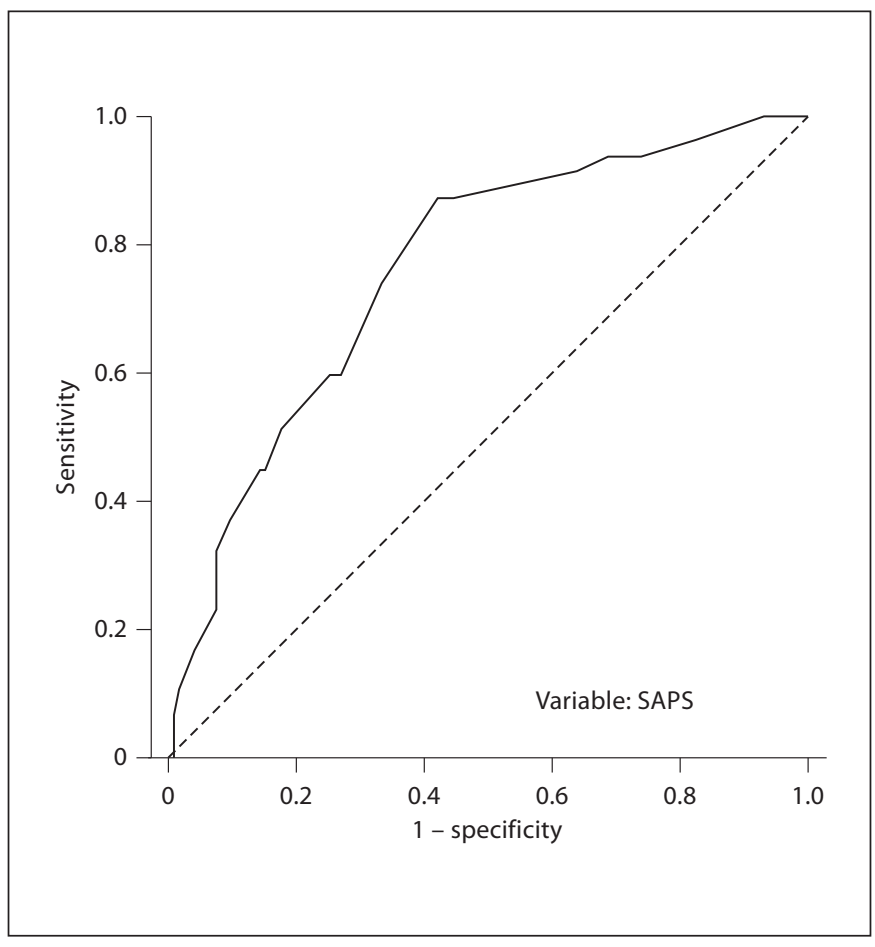

Fig. 6. Predictive value of the SAPS II regarding the risk of recannulation according to ROC analysis [AUC 0.725 (95\% CI: 0.634$0.815), \mathrm{p}<0.001]$.

Different techniques for decannulation and tracheostomy closure are currently employed in patients with prolonged ventilation $[13,15]$. To our knowledge, the TR has not yet been evaluated in larger populations, although it is established in many specialized weaning centers and enables effective NIV without leakage after decannulation, if needed [16]. A short observational study on the practicability of the TR [17] reported that its insertion was impossible in 7 of 15 patients (46.6\%) because of anatomical constraints. In contrast, we failed to insert the TR in only $12.6 \%(\mathrm{n}=24)$ of our study patients. In this context, innovative techniques such as oscillatory impedance measurement could probably be useful to avoid decannulation failure [18]. However, the TR was not considered in 194 of 384 patients with prolonged weaning (50.5\%), as they were clinically stable without threatening respiratory failure, already had a surgical tracheostoma or had died prior to decannulation.

The population studied had been on invasive ventilation via tracheostomy for 31 days on average, and $60 \%$ were finally discharged with ventilatory support $(43.6 \%$ 
noninvasive and $16.4 \%$ invasive HMV). Most patients also showed a number of comorbidities. Accordingly, we observed a relatively high rate of decannulation failure at the first trial $(28.3 \%, \mathrm{n}=47)$, which would be unacceptable for routine decannulation of patients who have completely recovered from a critical illness [19]. However, in a recent retrospective analysis of 135 patients transferred to a long-term acute care hospital, only $35 \%$ could be successfully decannulated [13]. Probably this relatively low decannulation rate was due to the specific study population (e.g. of greater age, more neurological diagnoses) or differences in the attitude towards long-term NIV after prolonged weaning. Nevertheless, it seems noteworthy that $80.6 \%$ of our patients could be liberated from tracheostomy by using the TR. This was clearly based on the safety backup provided by the TR which allowed a more progressive weaning approach. Of course, prospective controlled trials are needed to evaluate the different weaning strategies including the use of the TR in patients with prolonged weaning and persisting respiratory failure.

We also evaluated clinically useful predictors of decannulation success in our high-risk patients. Recently, Marchese et al. [15] reported that physicians of respiratory ICUs considered clinical signs such as sufficient swallowing and cough and objective respiratory parameters (respiratory rate, $\mathrm{S}_{\mathrm{aO}_{2}}, \mathrm{P}_{\mathrm{aO}_{2}}$, arterial carbon dioxide tension and $\mathrm{pH}$ ) as most important for the decision to close tracheotomy in patients with long-term ventilation. The authors concluded that these criteria and the optimal time point of decannulation should be further validated.

In our analysis, the duration of spontaneous breathing before decannulation was strongly associated with the need for recannulation. This was true for absolute values in terms of hours, but particularly for the proportion of spontaneous breathing within the last $24 / 48 \mathrm{~h}$ or since admission to the weaning center (fig. 4). Regarding the last $24 \mathrm{~h}$ before decannulation, there was an impressive relationship between decannulation failure and the duration of spontaneous breathing (fig. 5). Oxygenation in terms of $\mathrm{P}_{\mathrm{aO}}$ prior to decannulation and the need for NIV after decannulation were also predictive of decannulation failure. This demonstrates that the respiratory condition plays a pivotal role in the decannulation of highrisk patients. A higher SAPS II upon admission was also related to decannulation failure and had the highest predictive value in ROC analysis. However, analysis of the SAPS II items revealed that only $\mathrm{P}_{\mathrm{aO}_{2}} / \mathrm{F}_{\mathrm{iO}_{2}}$ and age were significant (data not shown). In line with this, age and severity of the disease on admission in terms of the Acute
Physiology and Chronic Health Evaluation II score have been revealed as major determinants for prolonged mechanical ventilation in COPD patients [20]. About $25 \%$ of our patients could be successfully liberated from tracheostomy, although their spontaneous breathing period was shorter than $6 \mathrm{~h}$. This success rate underlines the natural variability of single predictors, but from a clinical perspective seems to be too low as it implies recannulation in a considerable proportion of patients.

In addition, high creatinine levels were associated with decannulation failure. Correspondingly, renal function has been found as an independent predictor for successful weaning in patients with prolonged mechanical ventilation [21, 22]. Moreover, the duration of the preceding intubation and tracheostomy were associated with decannulation success. In line with this, Hsu et al. [23] recorded shorter intubation periods, length of ICU stay and posttracheostomy ICU stay in patients with successful weaning. An important finding was that recannulation delayed the discharge from the weaning center by as much as 14 days. This also highlights the clinical significance of predictors for successful decannulation.

To our knowledge only two studies have prospectively investigated criteria for decannulation during weaning. Ceriana et al. [24] used a flowchart (based on 6 clinical and physiological parameters) to decide on decannulation. However, their patients showed clinical stability and spontaneous breathing for at least 5 days. Accordingly, decannulation was successful in $78 \%$, whereas only 4 patients (5.6\%) were switched to NIV. In patients with predominantly neuromuscular disorders, Bach and Saporito [25] highlighted the patients' ability to produce a peak cough flow (PCF) $>1601 / \mathrm{min}$ as a criterion for extubation or decannulation. We did not assess PCF but evaluated effective coughing by clinical judgement. This has possibly contributed to the high need for recannulation caused by secretion problems. It is known, however, that aspiration is common in tracheostomized, long-term ventilated patients [26] and cannot be ruled out even when PCF appears sufficient.

In conclusion, our findings demonstrate the feasibility, efficacy and safety of the insertion of a TR in patients with prolonged weaning with a high risk for recurrent or persisting hypercapnic respiratory failure. In particular, the duration of unsupported breathing, oxygenation and age were predictors of decannulation failure. As these results are only observational, they should be validated in prospective clinical trials. 


\section{References}

1 MacIntyre NR, Epstein SK, Carson S, Scheinhorn D, Christopher K, Muldoon S: Management of patients requiring prolonged mechanical ventilation: report of a NAMDRC consensus conference. Chest 2005;128:3937-2954.

$>2$ Boles JM, Bion J, Connors A, Herridge M, Marsh B, Melot C, Pearl R, Silverman H, Stanchina M, Vieillard-Baron A, Welte T: Weaning from mechanical ventilation. Eur Respir J 2007;29:1033-1056.

$>3$ Divo MJ, Murray S, Cortopassi J, Celli BR: Prolonged mechanical ventilation in Massachusetts: the 2006 prevalence survey. Respir Care 2010;55:1693-1698.

4 Epstein SK: Anatomy and physiology of tracheostomy. Respir Care 2005;50:476-482.

$\checkmark 5$ Kornblith LZ, Burlew CC, Moore EE, Haenel JB, Kashuk JL, Biffl WL, Barnett CC, Johnson JL: One thousand bedside percutaneous tracheostomies in the surgical intensive care unit: time to change the gold standard. J Am Coll Surg 2011;212:163-170.

6 Heffner JE: Tracheostomy decannulation: marathons and finish lines. Crit Care 2008; 12:128.

$>7$ O'Connor HH, White AC: Tracheostomy decannulation. Respir Care 2010;55:10761081.

$>8$ Le Gall JR, Lemeshow S, Saulnier F: A new Simplified Acute Physiology Score (SAPS II) based on a European/North American multicenter study. JAMA 1993;270:2957-2963.

$>9$ Durbin CG Jr: Tracheostomy: why, when, and how? Respir Care 2010;55:1056-1068.
10 Griffiths J, Barber VS, Morgan L, Young JD: Systemic review and meta-analysis of studies of the timing of tracheostomy in adult patients undergoing artificial ventilation. BMJ 2005;330:1243

11 Engoren M, Arslanian-Engoren C, Fenn-Buderer $\mathrm{N}$ : Hospital and long-term outcome after tracheostomy for respiratory failure. Chest 2004; 125:220-227.

12 Aboussouan LS, Lattin CD, Kline JL: Determinants of long-term mortality after prolonged mechanical ventilation. Lung 2008; 186:299-306.

13 O'Connor HH, Kirby KJ, Terrin N, Hill NS, White AC: Decannulation following tracheostomy for prolonged mechanical ventilation. J Intensive Care Med 2009;24:187-194.

14 Marchese S, Lo Coco D, Lo Coco A: Outcome and attitudes toward home tracheostomy ventilation of consecutive patients: a 10-year experience. Respir Med 2008;102:430-436.

15 Marchese S, Corrado A, Scala R, Corrao S, Ambrosino N, Intensive Care Study Group Italian Association of Hospital Pulmonologists: Tracheostomy in patients with longterm mechanical ventilation: a survey. Respir Med 2010;104:749-753.

16 Hess DR: Tracheostomy tubes and related appliances. Respir Care 2005;50:497-510.

17 Rosenblüh J, Schönhofer B, Kemper P, Voshaar T, Köhler D: Bedeutung von Platz haltern tracheotomierter Patienten während der Entwöhnungsphase nach Langzeitbeatmung. Med Klin (München) 1994;89:61-63.

18 Franke KJ, Nilius G, Morgenstern S, Ruhle $\mathrm{KH}$ : Removal of the tracheal tube after prolonged mechanical ventilation: assessment of risk by oscillatory impedance. Respiration 2011;81:118-123.
19 Stelfox HT, Crimi C, Berra L, Noto A, Schmidt U, Bigatello LM, Hess D: Determinants of tracheostomy decannulation: an international survey. Crit Care 2008;12:R26.

20 Gursel GG: Determinants of the length of mechanical ventilation in patients with COPD in the intensive care unit. Respiration 2005;72:61-67.

-21 Abboussouan LS, Lattin CD, Anne VV: Determinants of time-to-weaning in specialized respiratory care unit. Chest 2005;128: 3117-3126.

$22 \mathrm{Wu}$ YK, Kao KC, Hsu KH, Hsieh MJ, Tsai YH: Predictors of successful weaning from prolonged mechanical ventilation in Taiwan. Respir Med 2009;103:1189-1195.

23 Hsu CL, Chen KY, Chang CH, Jerng JS, Yu CJ, Yang PC: Timing of tracheostomy as a determinant of weaning success in critically ill patients: a retrospective study. Crit Care 2005;9:R46-R52.

24 Ceriana P, Carlucci A, Navalesi P, Rampulla C, Delmastro M, Piaggi G, De Mattia E, Nava $\mathrm{S}$ : Weaning from tracheostomy in long-term mechanically ventilated patients: feasibility of a decisional flowchart and clinical outcome. Intensive Care Med 2003;29:845-848.

25 Bach JR, Saporito LR: Criteria for extubation and tracheostomy tube removal for patients with ventilatory failure. A different approach to weaning. Chest 1996;110:15661571.

26 Schönhofer B, Barchfeld T, Haidl P, Köhler D: Scintigraphy for evaluating early aspiration after oral feeding in patients receiving prolonged ventilation via tracheostomy. Intensive Care Med 1999;25:311-314. 